\title{
Chronicle workshops as data collection method in evaluation of national work environment intervention
}

\author{
Kirsten Olsen ${ }^{1[0000-0001-8349-1535]}$, Mark Lidegaard ${ }^{1}$ and Stephen Legg ${ }^{1}$ \\ ${ }^{1}$ Centre for Ergonomics Occupational Safety and Health, School of Health Sciences, Massey \\ University, Palmerston North 4442, New Zealand \\ k.b.olsen@massey.ac.nz
}

\begin{abstract}
When evaluating national work environment initiatives, it is important to choose methods through which it is possible to gather necessary and relevant information in a time efficient way for researchers and involved organisations. This article evaluates the usefulness of chronicle workshops as a data collection method to help assess the effectiveness of national work environment initiatives aiming to create interventions in organisations. Chronicle Workshops were used as one of three methods in case studies evaluating a national guideline on moving and handling people. Chronicle workshops were found to be an efficient method to identify specific interventions, when they occurred, who had been instrumental in implementing them, what contextual factors had influenced the intervention and factors facilitating and hindering intervention. They lacked specificity on individual strategies and why these did or did not work. Thus Chronicle workshops are good at creating an overview of implementation efforts but need to be supplemented with other methods to gain more detailed information.
\end{abstract}

Keywords: Participation, Moving and handling patients, Realist analysis.

\section{Introduction}

This article evaluates the usefulness of chronicle workshops as a data collection method to help assess the effectiveness of national work environment initiatives aiming to create interventions in organisations. These initiatives are complex interventions [1] because organisations are influenced by an ever changing environment with multiple initiatives occurring at the same time and further because implementation in an organization is influenced by many factors on many levels with feedback loops changing the organizational context. Often evaluations take place after the national initiative has been launched. This makes it even more difficult to assess the process of implementation, what influenced the implementation and what the outcomes were. To evaluate a national initiative aimed at organizational intervention it is important to evaluate how and if the initiative reaches the target organisations, what makes the organisations decide to initiate interventions, how the intervention is implemented, what influences the implementation, to what extent the implementation is completed, what the outcome is, and what has influenced it. 
This article only looks at how chronicle workshops, as a method, can help identify the implementation process in an organisation and what influenced this process- both in a positive and negative way.

The chronical workshops were used in a project that evaluated the uptake, use and effect of a national guideline for moving and handling people (MHP): "Moving and handling people: The New Zealand guidelines” [2], launched in 2012. The project consisted of three phases: 1) Evaluation of national injury claims rates and costs related to moving and handling people over an eleven years period [3]; 2) Evaluation of the awareness, uptake and use of the guidelines through a questionnaire survey to intended users [4, 5] and; 3) Evaluation of factors facilitation and hindering implementation of the guidelines in hospitals using a case study approach [6]. The chronicle workshops were used in the case studies in phase three. The aim of the third phase and the case studies was to identify what made the MHP guidelines work or not work for different organisations and under what circumstances.

The article describes what a chronicle workshop is, the purpose and use of the chronicle workshops (organizing, conduction and extracting findings), the outcome of the workshops (what types of data were extracted) and finally includes a reflection on the usefulness of the chronicle workshops in relation to the purpose.

\section{Chronicle workshops}

The chronicle workshops were used in a mixed method multiple case study. A large public hospital and a small private hospital were selected as case study organisations. Each case study consisted of in-depth semi-structured interviews, a chronicle workshop and document analysis. Chronicle workshops have previously been used to create the shared history of an organization to visualise and retrieve information about the past, reviewing the history and creating a common explanation and understanding of the organization $[7,8]$.

\subsection{Aim of the chronicle workshops}

The aims of the chronicle workshops were to establish how the MHP guidelines and MHP related initiatives had been implemented to manage risk factors related to MHP and identify factors that had facilitated or hindered the implementation and impact over the period $2007-2017$.

\subsection{Organising the chronical workshops}

The organisations were informed about the methods, including the chronicle workshop and time commitment before they agreed be part of the project. Initially three semistructured interviews were conducted with a senior manager, a health and safety (H\&S) manager and a MHP coordinator. Part of these interviews explored who it would be appropriate to invite to the chronicle workshops. The MHP coordinators contacted and invited prospective participants and informed them about the purpose. A time for the 
workshops that suited the people that decided to participate was identified. The intention was that the participants would cover different job roles that had influence or had been affected by the implementation, to give a diverse perspective on the implementation process [9]. We aimed to include participants to balance: common reference (same organisation, knowledge about MHP); length of service (including some employed before 2007); position in the organisation (from senior management to frontline people); expertise within MHP (people involved with implementation and people conducting MHP). The participants from the two hospitals are presented in Table 1.

The MHP coordinators organized a suitable room with a large plain wall big enough to indicate a ten-year period with A4 sheets of paper. Each workshop lasted 4 hours. Coffee, tea and food were provided.

Table 1. Participants at the two chronicle workshops.

\begin{tabular}{|c|c|c|c|}
\hline Participants: Private hospital & $\begin{array}{l}\text { Tenure } \\
\text { (years) }\end{array}$ & Participants: Public hospital & $\begin{array}{l}\text { Tenure } \\
\text { (years) }\end{array}$ \\
\hline Hospital general manager & 2 & Clinical nurse educator & 15 \\
\hline Theatre manager & 14 & Physiotherapist in a ward & 4 \\
\hline Quality Development Manager & 10 & $\begin{array}{l}\text { Physiotherapist in community } \\
\text { service }\end{array}$ & 10 \\
\hline Contracted radiographer & 10 & Moving and handling advisor & 3 \\
\hline $\begin{array}{l}\text { Health and safety representative } \\
\text { (theatre staff) }\end{array}$ & 25 & $\begin{array}{l}\text { Safe handling representative } \\
\text { (emergency) }\end{array}$ & 7 \\
\hline \multirow[t]{3}{*}{$\begin{array}{l}\text { Health and safety representative } \\
\text { (administrative staff) }\end{array}$} & 10 & $\begin{array}{l}\text { Safe handling representative } \\
\text { (ward) }\end{array}$ & 7 \\
\hline & & $\begin{array}{l}\text { Health and safety and safe han- } \\
\text { dling representative (Neonatal) }\end{array}$ & 10 \\
\hline & & Nurse employee representative & $20+$ \\
\hline
\end{tabular}

\subsection{Conducting the chronicle workshop}

All participants sat in a half-moon facing towards the wall (see figure 1). The chronicle workshops were divided into two main phases: Exploration and Interpretation.

The exploration phase consisted of three sessions with separate topics: i) What significant events have marked MHP as a priority at the hospital, and when?; ii) Which stakeholder, entities or institutions have characterised and driven the development and implementation of MHP programmes at the hospital, and when?; iii) What kind of initiatives and debates have arisen during the development and implementation of the MHP programme at the hospital, and when?

The facilitator presented the topic and invited clarifying questions at the beginning at each session. The participants wrote their personal inputs on 'sticky' notes, one issue per note. The notes for each session had different colures. The participants could write on as many notes as they needed within the time of five to ten minutes. The participants then took turns at placing their note(s) on the wall and briefly explained what the note was about. At the end of the session, they had the opportunity to ask clarifying questions. Additional notes could also be added to the wall. 
The interpretation phase consisted of two sessions: i) plenum session,- interpretation of key trends in the collective history of MHP at the hospital, - dividing the history into chapters; ii) group session, - identification of factors that facilitated or hindered the process of implementing MHP initiatives.

In the plenum session, the participants identified trends in MHP for different time periods, and created headings reflecting the trends for the periods. These heading were placed on the wall. A plenary discussion of the headings resulted in agreed headings for each time period. In the group session, the participants were divided into groups of people with similar background and experience. The groups analysed and interpreted the history, identified factors that facilitated or hindered the process of implementing MHP initiatives related to the different events. They wrote notes for each factor that they identified. The groups placed the notes on the wall and described each factor.

At the end of the workshop, the participants reflected on the workshop and contributed with any additional comments. Table 2 outlines the structure of the workshop.

Table 2. Structure of the chronicle workshops

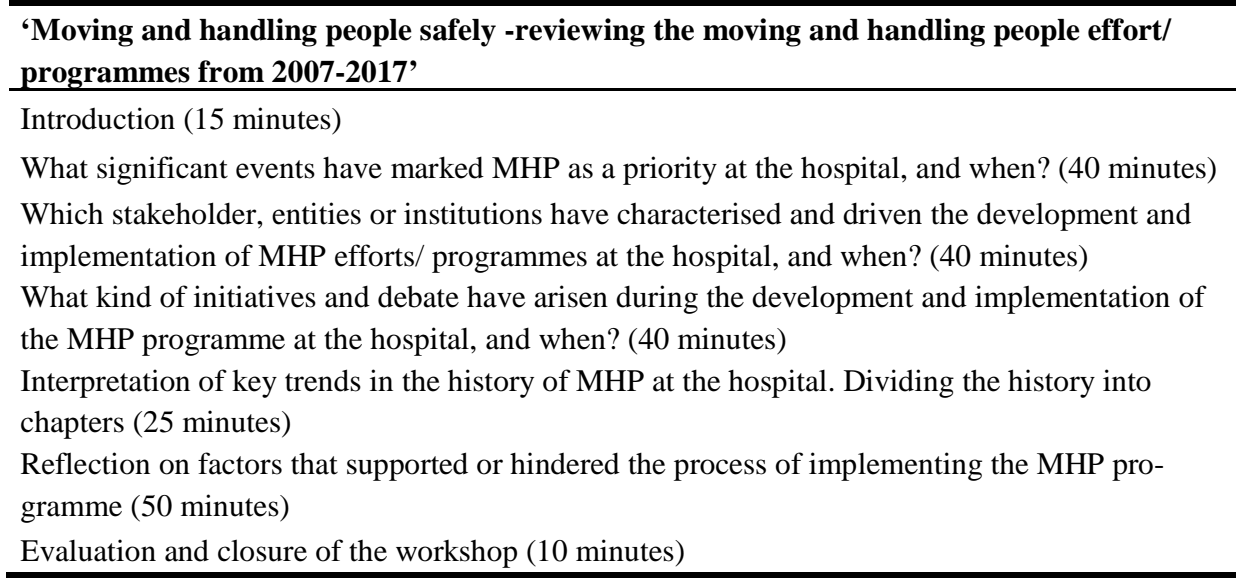

Three researchers facilitated the workshop. One led the process. One took written notes and photographed the wall with the timeline. One helped by facilitating the process and in identifying themes when they emerged from discussions in plenum.

The outcome of the chronicle workshops were timelines on the wall, with headings and notes in different colours showing significant events (yellow notes), stakeholders driving development and implementation (blue notes), initiatives and debates during the development (orange notes), factors facilitating implementation (green notes) and factors hindering implementation (red notes) (see Figure 2). To be able to document the chronicle workshops and their outcomes, the sessions were voice-recorded, notes were taken and the wall was photographed after each session. 


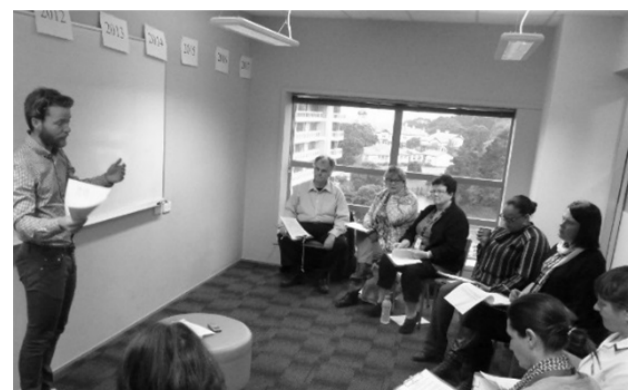

Fig. 1. Introduction to the chronicle workshop. The setup of the venue.

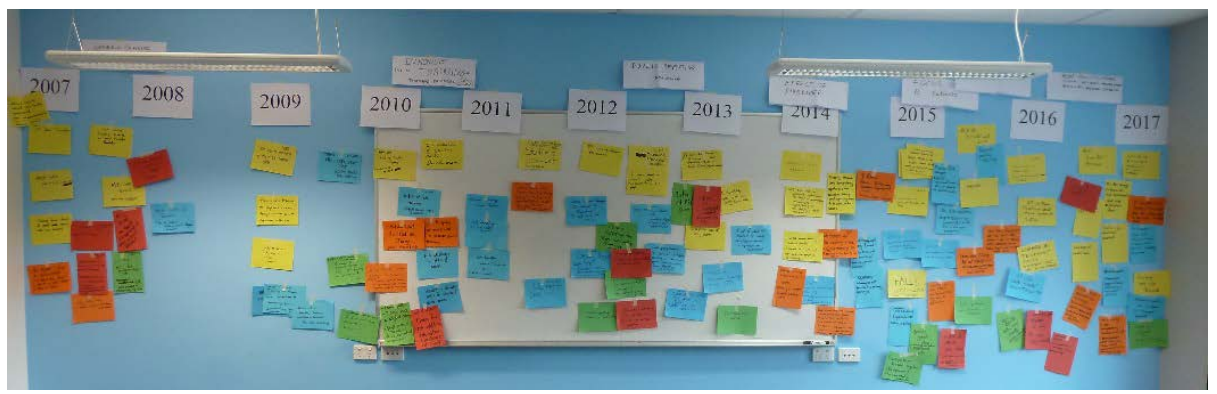

Fig. 2. The final timeline at the end of the chronicle workshop

\subsection{Extracting findings - writing the story}

The photographs of the timeline on the wall (Figure 2) were transferred to a digital picture in Prezi. The written notes were transcribed. One researcher listened to the voice recordings, consulted the notes and digital picture and wrote the story chapter by chapter. Each chapter contained a narrative and a table summarizing significant events, stakeholders, initiatives and debates, and factors facilitating and hindering implementation of MHP. The participants were sent a draft of the story and had the opportunity to comment on it. The story was then revised. Thus, each story reflected the joint experience of the workshop participants.

\section{Outcomes of the Chronicle Workshops}

Outcomes of the workshops are presented in two separate sections. Section 3.1 presents results from the workshop at the private hospital, and section 3.2 from the public hospital. Story chapters, significant events and related stakeholders, are presented in Tables 3 and 4. Initiatives and debates, and factors facilitating and hindering MHP implementation are illustrated by short descriptions of selected events following each table. 


\subsection{Outcomes of the Chronicle Workshop at the Private hospital}

Table 3 identifies the story chapters, events and stakeholders for the private hospital.

Table 3. Chapters of the private hospital's story about implementation of a moving and handling people programme 2007-2017, showing important events and influential stakeholders

\begin{tabular}{|c|c|}
\hline Events & Stakeholders \\
\hline \multicolumn{2}{|c|}{2007 - 2009: Getting together - Period leading up to the merge } \\
\hline Introduction of National MHP Programme & National H\&S manager \\
\hline Upgrading MHP equipment & $\begin{array}{l}\text { National office; Senior management; H\&S repre- } \\
\text { sentatives (reps.) }\end{array}$ \\
\hline Hospital rebuild & National office; CEO of the private hospital \\
\hline Merge of two private hospitals & National office; the two CEOs \\
\hline Updating local Policy & H\&S reps. \\
\hline l change & H\&S reps. \\
\hline \multicolumn{2}{|c|}{ 2010: New team } \\
\hline Creating consensus & The private hospital \\
\hline \multicolumn{2}{|c|}{2010 - 2012: Consolidation } \\
\hline Policies- Ch & Quality Development a \\
\hline anisational structure & Private hospital; H\&S reps. \\
\hline Continuous improvement of equipment & Private hospital; H\&S reps. \\
\hline \multicolumn{2}{|c|}{ 2012: Wake up } \\
\hline Organisational audit & Private hospital, Senior management team \\
\hline \multicolumn{2}{|c|}{2012 - 2015: Activation - Consolidating MHP standardisation } \\
\hline Appointment of MHP coordinator & Private hospital, Senior management team \\
\hline Sharing knowledge and specialist roles & National office; Senior management; H\&S reps. \\
\hline Reporting injuries & National office; H\&S reps, MHP coordinator \\
\hline $\begin{array}{l}\text { Communication with Accident Compensa- } \\
\text { tion Corporation }\end{array}$ & $\begin{array}{l}\text { National office; Accident Compensation Corpora- } \\
\text { tion }\end{array}$ \\
\hline \multicolumn{2}{|c|}{2015 - 2017: Evolution } \\
\hline Development of the organisation & Private hospital, CEO \\
\hline Consolidation of policies and procedures & Private hospital, CEO; H\&S reps. \\
\hline New H\&S legislation & National office \& H\&S manager, Private hospital \\
\hline Increased openness about injuries & H\&S reps \\
\hline Keep focus on MHP & H\&S reps, MHP coordinator \\
\hline
\end{tabular}

Debates and initiatives, facilitating and hindering factors.

One event (2007-09) that influenced the private hospitals implementation of MHP programme was the merge with another local hospital that was not part of the national chain. The influential stakeholders were the national office and the two CEOs. This event was related to "updating local policy" and "culture change". For these two events, H\&S representatives (reps.) were identified as influential stakeholders. Discussions about which H\&S and MHP policies were relevant in the new hospital were identified as debates related to the merge and "merge of two cultures" was identified as a facilitating factor. No hindering factors were identified. A debate identified in relation to "updating local policy" was an increased awareness of new needs related to MHP. "Change in design of the facility" (which was also mentioned as an event in Table 3: 
"Hospital rebuild") was identified as a facilitating factor. An initiative and debate related to "Culture change" was that staff and particularly H\&S reps. focused on getting the best out of the two different cultures and changing the 'them and us' terminology. An increased emphasis on H\&S reps.' work was identified as a facilitating factor. Poor communication and resistance to change were identified as hindering factors.

An important event (in the period 2012-15) was the 'appointment of MHP coordinator', where the influential stakeholders were the private hospital and the senior management team. No initiatives and debates were related to this event and no hindrance were identified, but two facilitators were identified; that the senior management team was involved and the small size of the organisation. It was not described how this event influenced MHP.

The National Office and the national H\&S manager were identified as key stakeholders initiating changes following the implementation of the new health and safety legislation (2015-17). The national H\&S manager organised workshops about the legislation, which informed the private hospital to assess where they did not comply with the legislation. The Management team for the Private hospital gave H\&S reps. the responsibility to find solutions to the gaps that were identified. The H\&S reps. were identified as key stakeholders in relation to "increased openness about injuries" (2015-17). This was related to debates about Managers' responsibility for H\&S triggered by the new H\&S legislation. The openness was facilitated by an increase in injuries resulting from MHP and a steadily aging workforce. The H\&S reps pushed for a more systematic discussion with the senior management team about injury trends, resulting in increased awareness of MHP risks and potential issues being addressed more rapidly.

\subsection{Outcomes of the Chronicle Workshop at the Public hospital}

Table 4 identifies the story chapters, events and stakeholders for the public hospital. Only the most distinct events are included because too many events were identified to present here. Some of the omitted events did not have identified related initiatives and debates or facilitating and hindering factors.

Debates and initiatives, facilitating and hindering factors.

Four events: "On-ward training profession specific"; Train the trainers \& ward trainers"; "Triannual trainer meetings"; "More area trainers on external courses" and; "Introduce 'Competency sign-off'” (2007-10), were driven by the MHP coordinator and supported by safe handling reps and MHP trainers. These events were related to the same initiatives and debates and were influenced by the same facilitating and hindering factors. The events focused on improving the MHP training and making it relevant to the attendees and their work, which made the training more, professional and increased staff attendance. The events were influenced by debates about who should drive safe MHP, if staff should lead the change and the training needs of staff. Factors that facilitated the events were a general support from middle management (which was higher on wards where managers previously had worked as clinicians) and passionate staff, educators and trainers. Heavy staff workload and insufficient time and resources for 
training were identified as hindering factors, negatively influencing the events and debates.

Table 4. Chapters of the public hospital's story about implementation of a moving and handling people programme 2007-2017, showing important events and influential stakeholders

\begin{tabular}{|c|c|}
\hline Events & Stakeholders \\
\hline \multicolumn{2}{|c|}{2007 - 10: Change in focus } \\
\hline Employment of MHP advisor & Public hospital \\
\hline Ceiling hoists and Electrical beds & Public hospital \\
\hline Changed 'On-bed transfer' & MHP advisor \\
\hline Increased use of sliding sheets & MHP advisor \\
\hline $\begin{array}{l}\text { On ward training profession specific, Train the } \\
\text { trainers \& Ward trainers }\end{array}$ & MHP advisor; Safe handling reps., \\
\hline $\begin{array}{l}\text { trainers \& Wara trainers } \\
\text { Triannual trainer meetings }\end{array}$ & MHP trainers \\
\hline More area trainers on external courses & MHP advisor; \\
\hline Introduce 'Competency sign-off' & MHP advisor; MHP trainers \\
\hline Weekly staff meeting & Staff, management \\
\hline \multicolumn{2}{|c|}{2010 - 12: Education \& accountability } \\
\hline Study days for safe handling reps & MHP advisor; Safe handli \\
\hline Nurse educators on the wards & Nurse educators; Safe handling reps \\
\hline Online training - videos and E-learning & ACC; MHP advisor \\
\hline Ward specific MHP programme & Safe handling reps. \\
\hline H\&S reps for individual work areas & Hospital board; MHP advisor; H\&S reps. \\
\hline H\&S at monthly ward meetings & $\begin{array}{l}\text { H\&S manager; Safe handling reps; Central } \\
\text { nurse manager }\end{array}$ \\
\hline \multicolumn{2}{|c|}{2012 - 14: Public reporting \& discussion - Effect of a mine disaster } \\
\hline Increased obesity \& injuries - a public subject & The media; District health boards \\
\hline More MHP information and guidance & MHP advisor; Safe handling reps, ACC \\
\hline Recognition of impact of safe handling reps. & MHP advisor \\
\hline Biannually refresher training reduced & MHP advisor \\
\hline Safe handling reps at each area & Safe handling reps. \\
\hline Electronic incident reporting system & Hospital board; Safe handling reps; staff \\
\hline \multicolumn{2}{|c|}{$\begin{array}{l}\text { Incidents reviewed by manager, safe handling H\&S department; Clinical nurse manager; } \\
\text { reps, and H\&S department }\end{array}$} \\
\hline \multicolumn{2}{|c|}{ 2015: New H\&S legislation and a bariatric focus } \\
\hline Implementation of 'Bariatric bundle' & $\begin{array}{l}\text { Public hospital; Assistant director of nurs- } \\
\text { ing; MHP advisor }\end{array}$ \\
\hline Appointment of new MHP advisor & MHP advisor; Safe handling reps. \\
\hline Introduction of competency checks & $\begin{array}{l}\text { Operation officer; H\&S manager; Charge } \\
\text { nurse }\end{array}$ \\
\hline \multicolumn{2}{|c|}{2016 - 2017: A more holistic model } \\
\hline New operation officer and H\&S manager & Public hospital's board \\
\hline Forming a MHP board & H\&S manager; MHP advisor \\
\hline Letter from OT in MAPU & Equipment advisory board, MAPU OT \\
\hline Hover-matts & MHP advisor \\
\hline Sliding sheets at bed heads & MHP-advisor \\
\hline All new clinical staff introduced to MHP & Safe handling reps. \\
\hline
\end{tabular}


The event "Weekly staff meeting” (2007-10) is different. It was the forum for debates about the trade-off between time and staff allocation and safety, and whether staff and patient safety could go hand-in-hand. These debates were influenced negatively by the work injury insurance experience rating scheme, heavy workload, insufficient time for training, poor staff attitude and buy-in to safe MHP practice, lack of vision from senior management, and that the health care sector focused on patient safety.

The events: "Letter from OTs"; "Hover-matts"; "Sliding sheets at bed heads" (2007-10) were influenced by the same debates and hindering factors. The debates were about how much equipment was needed to secure safe MHP. This debate had been present at the hospital earlier, just not mentioned earlier. A particular hindrance was a change in procurement policy that transferred the authority for procurement from the charge nurse to a central equipment advisory board. The board required a strong rationale to accompany procurement requests for it to be approved. This was a result of reduced budget and tighter regulation from the Ministry of Health. The reason they managed to introduce new equipment was that the MHP advisor was persistent and successfully managed to get approval for equipment purchase.

\section{Discussion}

Both chronicle workshops identified external (e.g. the new H\&S legislation) and internal events (e.g. hospital rebuild) that had influenced implementation of the hospitals MHP programmes and identified contextual factors at national, industry and organisational levels that had influenced the implementation. They also identified stakeholders and influential people, but did not describe these influential people's strategies to overcome the barriers that were identified.

For example, the chronicle workshop at the private hospital identified resistance to change and the MHP advisor as an influential stakeholder. During the interviews with a Senior manager, the National H\&S manager and the MHP advisor, it was described how the MHP coordinator had been influential in overcoming resistance to change and the strategy she had employed. She engaged with two of the senior managers and got them on board to support MHP. She changed staff's attitude and behaviour towards safer MHP by taking a team approach and working with staff on the floor.

The workshops did not describe in any way how the MHP guidelines had been used. Rather, this was identified through interviews with MHP advisors and H\&S managers. These showed that the MHP guidelines were used to check the programme elements that the hospitals had already implemented and to support the H\&S managers or MHP advisors involvement in renovation projects and new facilities. The H\&S manager at the public hospital also used them to support suggested changes to MHP training.

The workshops revealed that some professions, and some individual ward managers acted as barriers for implementation. Others might have functioned as barriers but only people not participating in the workshop were mentioned as barriers.

The chronicle workshops were organised by the MHP advisors and it was difficult to get enough participants to participate. It was also difficult to ensure that all relevant types of stakeholders were present. It was easier at the smaller private hospital than for 
the larger public hospital. The participants at the public hospital were mostly staff rather than managers involved in the MHP programme as trainers, H\&S reps or safe handling reps. It was not possible to get participants from procurement or facilities management. This was partly due to the time commitment the chronicle workshops required.

\section{Conclusion}

Chronicle workshops used in the present project were a good method to identify interventions and when they occurred, and who had been instrumental in the implementation. They provided good information on contextual factors, important events and factors that hindered and facilitated the implementation. However, they did not provide enough details about individual strategies and why they worked or did not work. Thus in conclusion, chronicle workshop is a good method to gain an overview of implementation effort but details need to be collected via other methods to inform how national programmes can help implementation in organisations.

\section{References}

1. Rogers, P.J., Using programme theory to evaluate complicated and complex aspects of interventions. Evaluation, 2008. 14(1): p. 29-48.

2. Accident Compensation Corporation, Moving and handling people: The New Zealand guidelines. 2012, Wellington: Accident Compensation Corporation.

3. Olsen, K.B., M. Lidegaard, and S. Legg, Assessment of the uptake and impact of the ACC New Zealand Moving and Handling People Guidelines (2012) - Stage 3 report - Trends in injury claims and claims cost related to moving and handling people 2005 - 2016. 2017: Palmerston North.

4. Olsen, K.B., M. Lidegaard, and S. Legg, Assessment of the uptake and impact of the ACC New Zealand Moving and Handling People Guidelines (2012). Stage 2 Uptake and use - Part A: Descriptive analysis of questionnaire findings. 2016, Massey University.

5. Olsen, K.B., M. Lidegaard, and S. Legg, Assessment of the uptake and impact of the ACC New Zealand Moving and Handling People Guidelines (2012). Stage 2 Uptake and use - Part $B$ : Analysis of questionnaire findings stratified by role in relation to moving and handling people and by sub-sector in health care. 2017, Massey University.

6. Olsen, K.B., M. Lidegaard, and S. Legg, Assessment of the uptake and impact of the ACC New Zealand Moving and Handling People Guidelines (2012). Stage 4 Factors facilitating and hindering implementation and impact of the MHPG and MHP programme elements: Case study report. 2017, Massey University.

7. Gensby, U., Assessing the present in perspective of the past: Experiences from a Chronicle Workshop on company-level work Disability Management. Nordic journal of working life studies, 2014. 4(2): p. 85-115.

8. Hansen, A.M. and M.H. Pedersen, Vidensproduktion, positionering og magt $i$ historievcrksteder. Tidskrift for arbejdsliv, 2014. 16(3): p. 23-37.

9. Limborg, H.J. and H. Hvenegaard, The Chronicle workshop, in Facilitating Change, L.B. Rasmussen, Editor. 2011, Polyteknink Forlag: Denmark. 
Chronicle Workshops as Data Collection Method in Evaluation of National Work Environment Intervention

\author{
Olsen, K
}

2019-01-01 